\title{
Urban-Rural Disparities in Informal Care Intensity of Adult Daughters and Daughters-in-Law for Elderly Parents from 1993-2015: Evidence from a National Study in China
}

\author{
Yi Wang ${ }^{1} \cdot$ Jiajia $\mathrm{Li}^{1} \cdot$ Nan Zhang $^{2} \cdot$ Lulu Ding $^{1} \cdot$ Yuejing Feng ${ }^{1} \cdot$ Xue Tang $^{1} \cdot$ Long Sun $^{1}$. \\ Chengchao Zhou ${ }^{1,3}$
}

Accepted: 20 January 2020 / Published online: 27 January 2020

(C) The Author(s) 2020

\begin{abstract}
The Chinese population is ageing and the burden of caregiving for elderly on society is getting heavier. With formal long-term care system underdeveloped, informal care provided by family members remains the predominant form of care provision in China. Urban and rural caregivers may face different situations in their informal caring roles due to China's strict household registration system (hukou). There are few studies focusing on rural-urban disparities in elderly care from the perspective of female caregivers. We used hukou status rather than living location to distinguish urban and rural, and the informal care was divided into low-intensity and high-intensity in our study. We used repeated cross-sectional data from the China Health and Nutrition Survey (CHNS). Multinomial logistic regressions and Oaxaca-Blinder decomposition techniques were used to explore the urban-rural disparities. We found that respondents with urban hukou were around $30 \%$ more likely to provide informal care than those with rural hukou, and the relative risk ratios value for both low $(\mathrm{RRR}=1.29)$ and high $(\mathrm{RRR}=1.30)$ intensity care were significantly at $5 \%$ level. The results of the Oaxaca-Blinder decomposition showed that the mean difference of informal care time between urban and rural was 3.11. Among them, education attainment can explain $25.10 \%$ of the total difference between urban and rural and was the largest contributor to the overall gap. Long-term care system in China should be established and improved, and policies should focus more on the most vulnerable groups such as rural hukou holders and the less-educated.
\end{abstract}

Keywords Informal care $\cdot$ Elderly $\cdot H u k o u$ status $\cdot$ China

\section{Introduction}

The Chinese population is continually ageing and the burden of caregiving for elderly on society is getting heavier (Du and Yin 2012; Lin 2014; Yang et al. 2016). The number of the elderly aged 65 and above had reached 167 million (11.9\% of China's total population)

Chengchao Zhou

zhouchengchao@sdu.edu.cn

Extended author information available on the last page of the article 
in 2018 and is expected to grow to $22.6 \%$ by 2040 (Zeng et al. 2019). The aged dependency ratio (number of people age 65 and above/number of people age 15-64) was 16.8\% (National Bureau of Statistics of China 2018) and the proportion of older people requiring daily care is estimated to increase up to $60 \%$ by 2050 (World Health Organization 2016). The rapid aging issue in China has brought about far-reaching implications on its health and social welfare system ( $\mathrm{Li}$ and Otani 2018). Long-term care is important for frail older adults, which is defined as a systematic activity according to The World Health Organization (WHO), undertaken by informal caregivers (family members, friends or neighbors) or formal caregivers (such as professional medical institutions), to ensure that individuals who are incapable of fully caring for themselves maintain a high quality of life (World Health Organization 2015). The development of formal long-term care system is still in early stages in China (Hu 2018) due to lack of professional caregivers and institutions. According to the 2018 China health statistics yearbook and the Statistical bulletin on the development of civil affairs, there were only about 3.8 million registered nurses in China, with 2.7 nurses per thousand people; only 29.1 beds provided by nursing homes for every thousand elderly people by the end of 2018. The supply of formal care is far from enough. As a consequence, formal care in China is unlikely to be the dominant model in short term and informal care remains the majority of long-term care.

Informal care mainly plays a key role not only for the elderly but for the society (Chen et al. 2015). In the first place, informal care is generally considered to be effective in improving health and wellbeing of elderly people (Wu and $\mathrm{Lu} 2017$ ). In particular, caregiving provided by adult children can improve the mental health of older people (G. Wang et al. 2017). In the second place, most of the elderly prefer to live in their own homes rather than residential care homes (Wong and Leung 2012). Although some studies indicate that informal care may reduce the labor market participation of caregivers (Schmitz and Westphal 2017), other studies have shown that looking after older parents may improve adult children's happiness (van Campen et al. 2013). For the society, informal care can relieve the stress of public finances (World Health Organization 2016; Van Houtven and Norton 2008). Although China has released some documents (National Health Commission of the People's Republic of China 2019; The State Council 2019) to improve the formal long-term care system in recent 2 years, these policies still in its infancy and tend to target the disabled elderly. In the absence of formal support systems in China, as an important alternative ( $\mathrm{Lu}$ et al. 2015), informal caregiving for older adults is becoming increasingly important.

Urban and rural caregivers may face different challenges in their informal caring roles in China. For example, rural caregivers may be disadvantaged because they may be completely lacking in health care services (Zhou and Tian 2011; Meina et al. 2007). There are also significant differences between urban and rural areas in terms of residential arrangements and the number of children available for intergenerational family support ( $\mathrm{Xu}$ and Chi 2010). On the one hand, compared with the rural, the implementation of family planning policy in urban is stricter in China, which leads to a smaller family size and fewer support available for elderly support (Shi 2014). On the other hand, China has been undergoing rapid urbanization and rural-to-urban migration (mainly undertaken by working age population) that may erode the filial piety culture and intergenerational family support available for older people in rural China (Yang 2007). As such, it is of great practical significance to analyze the difference of caregiver's informal care for the elderly from the perspective of urban-rural disparities.

Previous studies on informal care for urban-rural disparities focus mainly on developed countries. For example, Bédard et al. (2004) investigated the rural-urban differences in 
health impacts on caregivers (both men and women) in Canada, and they found there were no significant differences on health status and health behaviors between rural and urban caregivers. Kosloski et al. (2002) did a survey on the use of respite services between urban and rural caregivers in the United States and found that urban caregivers were more likely to use respite services than rural peers. Sung-Wan et al. (2010) investigated caregivers in Korea and found that urban residence was significantly associated with higher care burden than rural counterparts. However, the research in other socio-cultural contexts may not be translated into the Chinese context due to its substantial rural-urban gap and gendered roles of caregivers. Unlike the developed countries, China has established a strict household registration system (hukou). The hukou system divides the population into urban and rural whereas urban residents have exclusive access to social welfare such as education, healthcare, housing and employment, that are not available for rural Hukou holders (Wu and Treiman 2004) and even migrant workers with rural hukou who work in the cities. Hukou system has created a two-class society with sharp rural-urban distinctions (Treiman 2012) and exacerbates inequality between urban and rural (Liu 2005). Hukou status is a very important driver of inequalities in rights and privileges affecting social wellbeing between rural and urban residents in China (Wu 2011; Treiman 2012; Guthrie 2011). Discrimination against rural hukou holders has adverse consequences, which are associated with poor health (Lei et al. 2014; Liu et al. 2015; Zhang and Treiman 2013) and restricted access to health care and social welfare for rural residents, and thus may increase the caregiving need for the elderly in the villages.

In China, women may be more sensitive to the care of the elderly than men because women have to bear more family care responsibilities and face more pressure to participate in social economic activities (Zhang 2012). China Statistics Bureau data (National Bureau of Statistics of the People's Republic of China 2012) have shown that women were 2.90 and 2.54 times more likely than men to do housework and to care for the elderly, respectively. Moreover, most of the studies have shown that married women usually undertake the role of primary caregivers for their parents in China due to both traditional gender norms and Confucian ideals of filial piety (Lan and Gong 2010; Zhang 2012; Yi et al. 2016). Therefore, it is particularly important to study the urban-rural disparities in informal care intensity with a focus on female caregivers. This paper intends to explore the urban-rural disparities in the intensity of informal care from the perspective of daughter and daughter-in-law for elderly parents in the Chinese context by drawing on a large-scale national survey.

\section{Method}

\subsection{Survey Design}

This paper used repeated cross-sectional data from the China Health and Nutrition Survey (CHNS) conducted by the University of North Carolina at Chapel Hill and the Chinese Center for Disease Control and Prevention. The CHNS was designed to examine the effects of the health, nutrition, and family planning policies and programs implemented by national and local governments and to see how the social and economic transformation of Chinese society is affecting the health and nutritional status of its population. It is the only large-scale, longitudinal study of its kind in China. This survey used a multistage, random cluster sampling in eight provinces (Liaoning, Jiangsu, Shandong, Henan, Hubei, Hunan, 
Guangxi, and Guizhou) to select a stratified probability sample (Zhang et al. 2014). This national survey had ten waves since 1989, but hukou information had only been provided since 1993 (Li et al. 2018). Thus, we used eight waves of data from 1993 to 2015 to analyze the informal care gap between urban and rural. For more details on sampling, design and approvals of the survey, please refer to Zhang et al. (2014). In this study, our inclusion criteria were women aged from 18 to 52 (because of the supplementary survey of CHNS on intergenerational linkages restricted to married women under the age of 52) with at least one living parent or parent-in-law in need of care. Parents or parents-in-law in need of care were identified mainly based on question "Does she/he (the parent/parent-in-law) need to be taken care of (in daily life and shopping)?', and was classified as 'yes' if the respondent answered yes. After merging different CHNS datasets, the final study sample of 2757 respondents with non-missing values on key variables was included in our analysis.

\subsection{Selection of Variables}

\subsubsection{Dependent Variable}

The outcome variable of this paper was the intensity of informal caregiving. Weekly hours of informal care were calculated from the question: "During the past week, how much time did you spend taking care of your parents or parents-in-law?" Based on the current literature (Chen et al. 2015; Carmichael and Charles 2003; Courtney Harold Van Houtven et al. 2013), we divided the intensity of informal caregiving provided by daughters or daughtersin-law into three categories: no-caregiving ( $0 \mathrm{~h} /$ week of caregiving), low-intensity caregivers (less than $10 \mathrm{~h}$ /week of caregiving), and high-intensity caregivers (more than $10 \mathrm{~h} /$ week of caregiving).

\subsubsection{Independent Variables}

The key independent variable was whether a respondent belongs to a rural or urban registration (hukou), which was based on the question "which type of household registration do you belong to." Socioeconomic characteristics (i.e. education attainment, household income and employment status) were controlled in our analyses. Education attainment was categorized as never attending any school, primary school, junior high school, high school, and university and above. We used inflation-adjusted annual household income per capita as our household income. Based on previous studies (McKenzie et al. 2010; Mei et al. 2013; Hanaoka and Norton 2008; Chen et al. 2015), we also added some demographic variables (e.g., age, marital status, number of parents who need cared for, number of siblings, type of caregiving relationship) in our analyses in order to adjust heterogeneities between rural and urban population. Marital status was categorized as married or divorced/ widowed. The type of caregiving relationship between the elder and the respondent was classified into three types: parents only, parents-in-law only or both. What's more, wave binary variables $(1993,1997,2004,2006,2009,2011,2015)$ were taken into account to capture the period effects of informal caregiving over time.

\subsection{Statistical Analysis Method}

All data analyses were performed using STATA 14.2 including descriptive statistics, multinomial logistic regressions and Oaxaca-Blinder decomposition techniques. 
We began our analysis by comparing the informal care intensity among urban and rural caregivers. Chi square tests for dichotomous variables and one-way analysis of variance for continuous variables. We reported $p$ values to examine whether there were statistically significant differences between urban and rural caregivers. We conducted multinomial logistic regression models to investigate the urban-rural disparities in different categories of informal care intensities adjusting for confounding variables. Relative risk ratios (RRR) were computed. Due to the characteristics of panel data, although it is generally assumed that the disturbance terms of different individuals are independent of each other, there is often autocorrelation between the disturbance terms of the same individual in different periods. In order to solve this problem, we use cluster-robust standard error to estimate standard error (Liu et al. 2010).

We used Oaxaca-Blinder (OB) decomposition to explain what contributed to rural-urban disparities in informal care. It was first introduced by Oaxaca (1973) and Blinder (1973) to investigate gender wage gaps in labor market. Oaxaca-Blinder decomposition method is widely used to explain how much of the difference in mean outcomes across two groups is due to group differences in the levels of explanatory variables, and how much is due to differences in the magnitude of regression coefficients. OB model is a counterfactual method with an assumption that "urban caregivers had the same characteristics as their rural counterparts". In this study, we used the weekly hours of informal care instead of the three levels of intensity caregiving Based on the OB model, divided the intensity caregiving gap between urban and rural into two main components as follows:

$$
\bar{Y}_{u}-\bar{Y}_{r}=\left(\bar{X}_{u}^{\prime}-\bar{X}_{r}^{\prime}\right) \hat{\beta}_{u}+\bar{X}_{u}^{\prime}\left(\hat{\beta}_{u}-\hat{\beta}_{r}\right)
$$

where $\bar{Y}_{u}$ and $\bar{Y}_{r}$ were the average outcome variable (weekly hours of informal care) for urban and rural; $\mathrm{X}$ is the explanatory variables; $\hat{\beta}_{r}$ and $\hat{\beta}_{u}$ denote the coefficients of explanatory variables for the urban and rural, respectively. Therefore, the rural-urban average hours of informal care gap can be attributed into two parts: explained part (due to differences in the levels of explanatory variables, also called endowment effect) and unexplained part (due to differences in the coefficients to explanatory variables, also called coefficients effect). The first term represents endowment effect, which is the percentage attributable to different levels of the explanatory factors between urban and rural hukou. The second term represents coefficient, which means the percentage attributable to explanatory factors having differential effects on informal care between urban and rural.

\section{Results}

\subsection{Descriptive Results}

Table 1 shows the descriptive results for the variables used in our research for the overall sample as well as the rural and urban subsamples. Across the study period, urban and rural respondents accounted for around $41.65 \%$ and $58.35 \%$ of the sample, respectively. Among urban caregivers, $23.87 \%$ provided low-intensity care and $19.77 \%$ provided high-intensity care, both higher than the $19.40 \%$ and $13.93 \%$ of women with rural hukou status. The total number of respondents whose parents or parents-in-law need to be cared for was 2756, of which 1286 (46.66\%) provided caregiving for their parents only, 1036 (37.59\%) only caregiving for parents-in-law, and $434(15.75 \%)$ provide caregiving for both parents and parents-in-law. According to Table 1 , we found a statistically significant difference in the type 
Table 1 Descriptive statistics

\begin{tabular}{|c|c|c|c|c|}
\hline Variables & All & Urban & Rural & $p$ value \\
\hline Total & 2756 & $1148(41.65)$ & $1608(58.35)$ & \\
\hline Intensity of caregiving & & & & $<0.001$ \\
\hline No caregiving & $1719(62.37)$ & $647(56.36)$ & $1072(66.67)$ & \\
\hline Low intensity $(<10 \mathrm{~h} /$ week $)$ & $586(21.26)$ & $274(23.87)$ & $312(19.40)$ & \\
\hline High intensity ( $\geq 10 \mathrm{~h} /$ week) & $451(16.36)$ & $227(19.77)$ & $224(13.93)$ & \\
\hline \multicolumn{5}{|l|}{ Socioeconomic characteristics } \\
\hline Education attainment & & & & $<0.001$ \\
\hline Illiteracy & $657(23.84)$ & $128(11.15)$ & $529(32.90)$ & \\
\hline Primary school degree & $527(19.12)$ & $114(9.93)$ & $413(25.68)$ & \\
\hline Junior school degree & $885(32.11)$ & $371(32.32)$ & $514(31.97)$ & \\
\hline High school degree & $388(14.08)$ & $270(23.52)$ & $118(7.34)$ & \\
\hline University degree or above & $299(10.85)$ & $265(23.08)$ & $34(2.11)$ & \\
\hline $\begin{array}{l}\text { Inflation-adjusted household income per } \\
\text { capita, mean (SD) (CNY in } 2015 \text { value) }\end{array}$ & $\begin{array}{l}10,560.99 \\
(14,104.99)\end{array}$ & $\begin{array}{l}13,530.52 \\
(15,285.93)\end{array}$ & $\begin{array}{l}8440.95 \\
(12,786.87)\end{array}$ & $<0.001$ \\
\hline Employment status & & & & $<0.001$ \\
\hline Unemployed & $839(30.44)$ & $391(34.06)$ & $448(27.86)$ & \\
\hline Employed & $1917(69.56)$ & $757(65.94)$ & $1160(72.14)$ & \\
\hline \multicolumn{5}{|l|}{ Demographic variables } \\
\hline Age of women, mean & $41.13(7.02)$ & $41.51(6.85)$ & $40.85(7.13)$ & 0.014 \\
\hline Marital status & & & & 0.332 \\
\hline Divorced/widowed & $81(2.94)$ & $38(3.31)$ & $43(2.67)$ & \\
\hline Married & $2675(97.06)$ & $1110(96.69)$ & $1565(97.33)$ & \\
\hline Type of caregiving for & & & & 0.034 \\
\hline Parents only & $1286(46.66)$ & $506(44.08)$ & $780(48.51)$ & \\
\hline Parents-in-law only & $1036(37.59)$ & $442(38.50)$ & $594(36.94)$ & \\
\hline Parents and parents-in-law & $434(15.75)$ & $200(17.42)$ & $234(14.55)$ & \\
\hline Number of parents who need & & & & 0.818 \\
\hline 1 & $2019(73.26)$ & $845(73.61)$ & $1174(73.01)$ & \\
\hline 2 & $534(19.38)$ & $216(18.82)$ & $318(19.78)$ & \\
\hline 3 & $129(4.68)$ & $53(4.62)$ & $76(4.73)$ & \\
\hline 4 & $74(2.69)$ & $34(2.96)$ & $40(2.49)$ & \\
\hline Number of siblings & & & & $<0.001$ \\
\hline 0 & $613(22.24)$ & $241(20.99)$ & $372(23.13)$ & \\
\hline 1 & $39(1.42)$ & $30(2.61)$ & $9(0.56)$ & \\
\hline 2 & $107(3.88)$ & $61(5.31)$ & $46(2.86)$ & \\
\hline 3 & $150(5.44)$ & $77(6.71)$ & $73(4.54)$ & \\
\hline$\geq 4$ & $1847(67.02)$ & $739(64.37)$ & $1108(68.91)$ & \\
\hline Age of care recipient & & & & 0.637 \\
\hline$<50$ & $52(1.89)$ & $20(1.74)$ & 32 (1.99) & \\
\hline$\geq 50$ & $2704(98.11)$ & $1128(98.26)$ & $1576(98.01)$ & \\
\hline Wave & & & & 0.027 \\
\hline 1993 & $265(9.62)$ & $98(8.54)$ & $167(10.39)$ & \\
\hline 1997 & $299(10.85)$ & $112(9.76)$ & $187(11.63)$ & \\
\hline 2000 & $368(13.35)$ & $166(14.46)$ & $202(12.56)$ & \\
\hline 2004 & $422(15.31)$ & $175(15.24)$ & $247(15.36)$ & \\
\hline
\end{tabular}


Table 1 (continued)

\begin{tabular}{cllll}
\hline Variables & All & Urban & Rural & $p$ value \\
\hline 2006 & $351(12.74)$ & $141(12.28)$ & $210(13.06)$ & \\
2009 & $280(10.16)$ & $104(9.06)$ & $176(10.95)$ & \\
2011 & $379(13.75)$ & $182(15.85)$ & $197(12.25)$ & \\
2015 & $392(14.22)$ & $170(14.81)$ & $222(13.81)$ & \\
\hline
\end{tabular}

$\chi^{2}$ Tests for categorical variables and analysis of variance for continuous variables. CNY: China Yuan

of caregiving relationship at 5\% level. The average age of respondents was 41 years old. There were significant differences between urban and rural in terms of all the control variables, especially in socioeconomic status (SES). The three indicators of SES, educational attainment, household income, and employment status, were all statistically significant difference in hukou type at $1 \%$ level. Urban hukou holders were better educated and had higher household incomes than their rural counterparts. Percentages of urban respondents had high school degrees and university degrees were $23.52 \%$ and $23.08 \%$, respectively, both higher than the percentage of rural hukou holders $(7.34 \%$ in high school degree and $2.11 \%$ in university degree). Urban hukou holders had an average annual income per capita of 13,531 China Yuan (CNY), compared with $8441 \mathrm{CNY}$ for rural hukou holders. Other details of descriptive results were shown in Table 1.

As indicated in Fig. 1, we describe the trend of rural-urban disparities from 1993 to 2015 in terms of informal caregiving. As shown in the figure, informal caregiving increased over time, rural-urban gaps in informal caregiving had persisted from 1993 to 2015 and urban hukou holders provided more caregiving for elderly than rural counterparts. In high-intensity caregiving, urban caregivers remained higher than rural and the gap tended to widen over the recent years, while this was not evident in low-intensity care.

\subsection{Multinomial Logistic Regression Analyses}

Table 2 presents the multinomial logistic regression results for urban and rural disparities in providing informal caregiving. No caregiving was chosen as the reference category. After controlling for the confounding variables, we found that respondents with urban hukou were around $30 \%(p<0.05)$ more likely to provide informal care than those

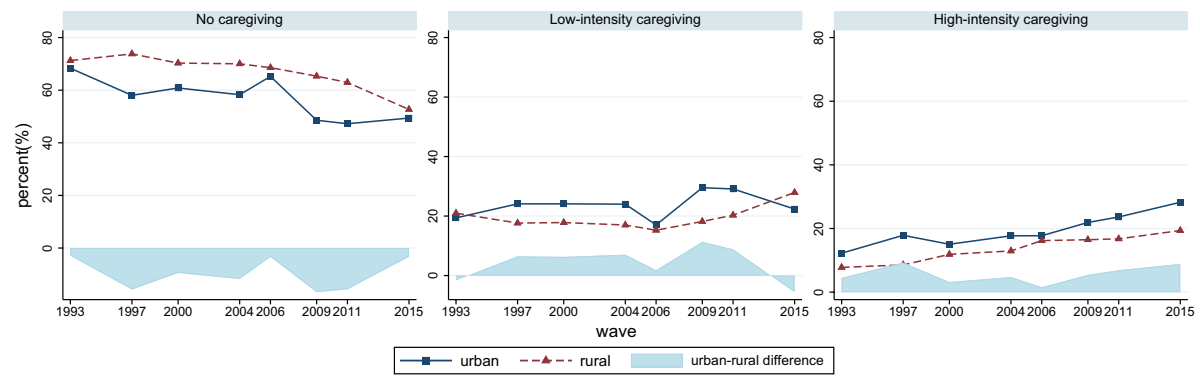

Fig. 1 Informal caregiving among urban and rural caregivers in China from 1993 to 2015 
Table 2 Multinomial logistic regression of women's informal care using pooled CHNS data from 1993 to $2015(\mathrm{n}=2756)$

\begin{tabular}{|c|c|c|c|c|}
\hline \multirow[t]{2}{*}{ Variables } & \multicolumn{2}{|c|}{ Low-intensity } & \multicolumn{2}{|c|}{ High-intensity } \\
\hline & RRR & $95 \% \mathrm{CI}$ & RRR & $95 \% \mathrm{CI}$ \\
\hline \multicolumn{5}{|l|}{ Hикои (reference: rural) } \\
\hline Urban & $1.29 * *$ & $1.03,1.62$ & $1.30 * *$ & $1.02,1.66$ \\
\hline \multicolumn{5}{|c|}{ Education attainment (reference: illiteracy) } \\
\hline Primary school degree & 0.90 & $0.66,1.22$ & 1.23 & $0.87,1.75$ \\
\hline Junior school degree & 1.11 & $0.84,1.46$ & 1.20 & $0.87,1.67$ \\
\hline High school degree & 1.33 & $0.94,1.88$ & $1.90 * * *$ & $1.30,2.77$ \\
\hline University degree or above & 1.14 & $0.76,1.71$ & $1.90 * * *$ & $1.24,2.90$ \\
\hline Household income per capita & 0.99 & $0.99,1.00$ & 1.00 & $0.99,1.00$ \\
\hline \multicolumn{5}{|c|}{ Employment status (reference: unemployed) } \\
\hline Employed & $1.30 * *$ & $1.04,1.62$ & 0.88 & $0.70,1.11$ \\
\hline Age of adult children & $1.02 * * *$ & $1.01,1.04$ & 1.00 & $0.99,1.02$ \\
\hline \multicolumn{5}{|c|}{ Marital status (reference: divorced/widowed) } \\
\hline Married & 0.79 & $0.45,1.41$ & 0.72 & $0.39,1.34$ \\
\hline \multicolumn{5}{|l|}{$\begin{array}{l}\text { Type of caregiving for (reference: } \\
\text { parents only) }\end{array}$} \\
\hline Parents-in-law only & $1.53 * * *$ & $1.24,1.89$ & $1.39 * * *$ & $1.09,1.78$ \\
\hline Both parents and parents-in-law & $2.95 * * *$ & $1.87,4.67$ & $1.64 * *$ & $1.05,2.56$ \\
\hline \multicolumn{5}{|c|}{ Number of parents who need (reference: 1 ) } \\
\hline 2 & $0.70 *$ & $0.49,0.99$ & $1.42 * *$ & $1.03,1.96$ \\
\hline 3 & 0.47 & $0.25,0.90$ & 1.10 & $0.58,2.09$ \\
\hline 4 & $0.26 * * *$ & $0.12,0.59$ & 0.64 & $0.29,1.43$ \\
\hline \multicolumn{5}{|l|}{ Number of siblings (reference: 0 ) } \\
\hline 1 & 1.61 & $0.54,4.77$ & 0.44 & $0.15,1.35$ \\
\hline 2 & 1.54 & $0.60,3.92$ & 0.71 & $0.31,1.62$ \\
\hline 3 & 1.09 & $0.43,2.72$ & 0.74 & $0.34,1.60$ \\
\hline$\geq 4$ & 1.15 & $0.50,2.66$ & 0.62 & $0.32,1.22$ \\
\hline \multicolumn{5}{|c|}{ Age of care recipient (reference: age $<50$ ) } \\
\hline$\geq 50$ & $2.72 * *$ & $1.06,7.01$ & $4.20 *$ & $0.95,18.64$ \\
\hline \multicolumn{5}{|l|}{ Wave (reference: 1993) } \\
\hline 1997 & 1.01 & $0.66,1.54$ & 1.30 & $0.75,2.26$ \\
\hline 2000 & 0.98 & $0.39,2.48$ & $2.26^{*}$ & $0.98,5.20$ \\
\hline 2004 & 0.90 & $0.36,2.26$ & $2.39 * *$ & $1.04,5.48$ \\
\hline 2006 & 0.68 & $0.26,1.73$ & $2.52 * *$ & $1.09,5.84$ \\
\hline 2009 & 1.17 & $0.46,3.01$ & $3.16^{* * *}$ & $1.35,7.39$ \\
\hline 2011 & 1.20 & $0.48,3.05$ & $3.11 * * *$ & $1.34,7.24$ \\
\hline 2015 & 1.39 & $0.55,3.49$ & $3.93 * * *$ & $1.73,8.93$ \\
\hline Constant & $0.03 * * *$ & $0.01,0.11$ & $0.03 * * *$ & $0.01,0.15$ \\
\hline
\end{tabular}

No caregiving as the reference group

$* * * p<0.01 ; * * p<0.05 ; * p<0.1$ 
with rural hukou, and the relative risk ratios value for both low $(\mathrm{RRR}=1.29)$ and high $(\mathrm{RRR}=1.30)$ intensity care was significantly at $5 \%$ level. As for the socioeconomic status, those with high school or university degree were about 1.90 times more likely than illiterate females to choose high-intensity care versus no care $(p<0.01)$, employed females were 1.30 times more likely than unemployed females to choose low-intensity care versus no care $(p<0.05)$. With respect to other demographic factors, older women were more likely to be low-intensity informal caregivers, but were not significantly in high-intensity caregiving. We also found that adult daughters-in-law provide more help to elders than do daughters, both in low-intensity and high-intensity care. Marital status of females showed no statistically significant differences both in high- and low-intensity care.

Table 3 presents the results of a multinomial logistic analysis of factors associated with different intensity caregiving between rural and urban. In terms of the education attainment, the multinomial logistic regression indicates that rural respondents who had high school degree were more likely to provide both high-intensity $(\mathrm{RRR}=2.28 ; p<0.01)$ and low-intensity $(\mathrm{RRR}=1.94 ; p<0.01)$ care, but they showed no statistically significant among urban females. Compared with unemployed urban respondents, employed urban respondents were more likely to provide low-intensity care $(\mathrm{RRR}=1.55 ; p<0.05)$, but they were less likely to provide high-intensity care $(\mathrm{RRR}=0.72 ; p<0.1)$. Compared with urban respondents, rural respondents were less likely to provide caregiving for their biological parents only. Among women with rural hukou, the likelihood of providing both high and low intensive care vs. no care were approximately 2.0 times $(p<0.01)$ greater for only taking care of parents-in-law caregivers relative to only taking care of biological parents caregivers. What's more, taking care of both biological parents and parents-in-law caregivers were 1.87 times more likely than only taking care of biological parents to choose high intensive care vs. no caregiving $(\mathrm{RRR}=1.87 ; p<0.1)$ and were 5.31 times more likely to choose low intensive care vs. no caregiving $(\mathrm{RRR}=5.31 ; p<0.01)$.

\subsection{Oaxaca-Blinder Decomposition Analyses}

The results of the Oaxaca-Blinder decomposition analysis were presented in Table 4. It shows that the mean time of informal care were $8.04(p<0.001)$ for urban caregivers and $4.93(p<0.001)$ for rural caregivers. Both endowments effect and coefficients effect were significant in OB decompositions. The total gap of the time of informal care between rural and urban was $3.11(p<0.001)$. The endowments effect was significant and the explanatory variables included in the model (i.e., education attainment, household income, employment status, age, marital status type of caregiving, number of parents who need cared for and number of siblings et al.) could explain $44.57 \%$ of the total rural-urban difference. In other words, if the rural groups were similar to the urban, in terms of the studied variables, the difference in providing informal care would decrease from 3.11 to 1.73 . In the explained part, education attainment was the most effective variables responsible for the rural-urban gap.

\section{Discussions and Conclusions}

To our knowledge, this is the first national study regarding informal care intensity from the perspective of daughter or daughter-in-law in China, and the rural-urban inequalities. The present study showed that urban women had higher proportion to provide informal care 


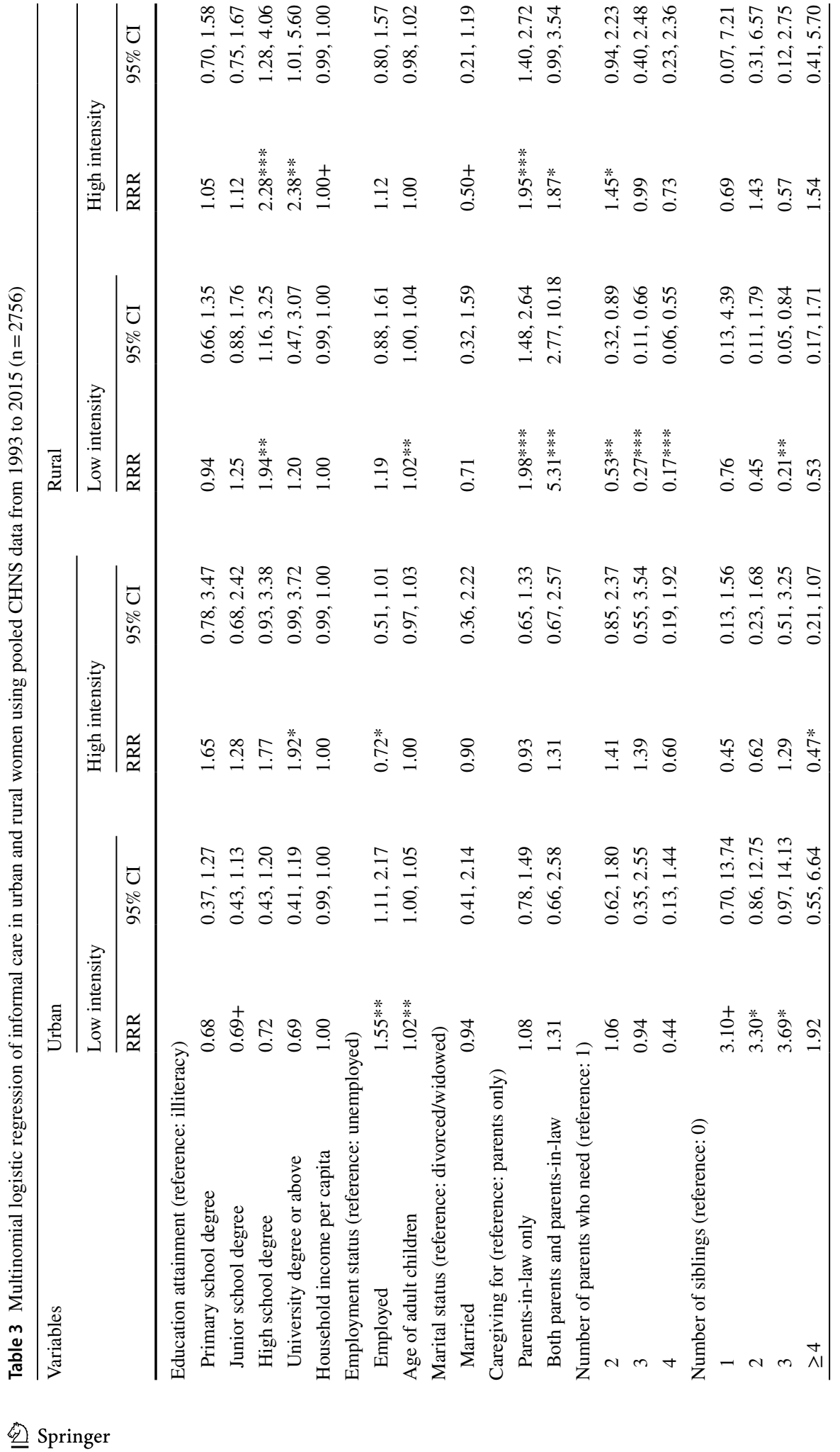




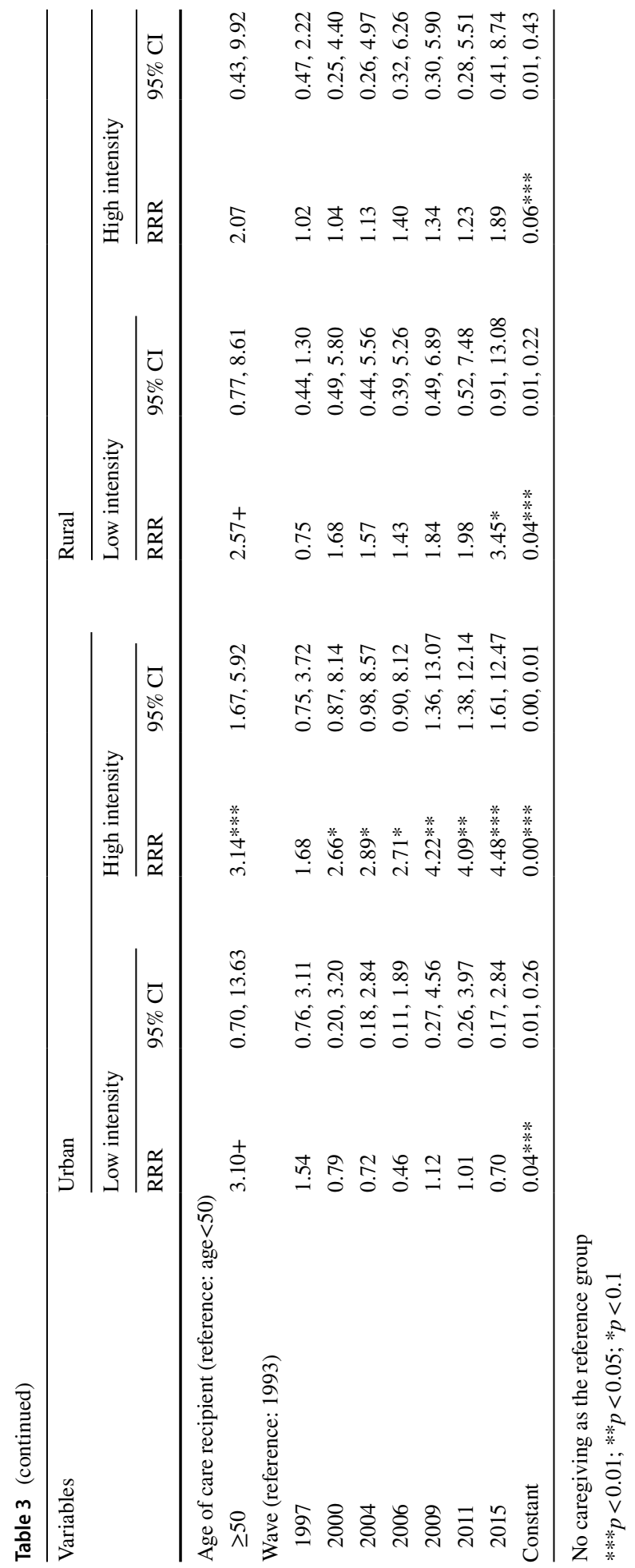


Table 4 Oaxaca- Blinder decomposition results between urban and rural caregivers

\begin{tabular}{llllr}
\hline & Coef. $(95 \% \mathrm{CI})$ & SE & Contrib. $(\%)$ & $p$ \\
\hline Mean time of informal care & & & \\
Urban & $8.043(6.595,9.491)$ & 0.739 & - & $<0.001$ \\
Rural & $4.932(4.135,5.728)$ & 0.406 & - & $<0.001$ \\
Difference (urban-rural) & $3.112(0.104,0.219)$ & 0.843 & 100.0 & $<0.001$ \\
Explained part & & & \\
Education attainment & $0.781(0.004,1.558)$ & 0.396 & 25.10 & $<0.001$ \\
Household income & $0.239(-0.592,1.069)$ & 0.424 & 7.68 & 0.573 \\
Employment status & $0.077(-0.034,0.190)$ & 0.058 & 2.47 & 0.184 \\
Age & $0.001(-0.071,0.071)$ & 0.036 & 0.05 & 0.990 \\
Marital status & $0.035(-0.054,0.124)$ & 0.046 & 1.12 & 0.443 \\
Type of caregiving & $0.015(-0.075,0.106)$ & 0.046 & 0.48 & 0.738 \\
Number of parents & $0.007(-0.145,0.159)$ & 0.078 & 0.22 & 0.929 \\
Number of siblings & $0.043(-0.081,0.167)$ & 0.063 & 1.38 & 0.497 \\
Age of care recipient & $0.005(-0.017,0.027)$ & 0.011 & 0.16 & 0.639 \\
Wave & $0.184(-0.045,0.412)$ & 0.117 & 5.91 & 0.115 \\
Total & $1.387(0.579,2.195)$ & 0.412 & 44.57 & 0.001 \\
Unexplained part & $1.725(0.072,3.377)$ & 0.843 & 55.43 & 0.041 \\
Total & & & &
\end{tabular}

than their rural counterparts, which was consistent with the majority of previous studies (Zhu and Osterle 2017; Rozario and Simpson 2018). These differences were apparent for the proportion as well as the probability after other variables were accounted for controlling for the confounding factors. We also found that women with urban hukou were more likely to provide informal care, both in low-intensity and high-intensity care, than their rural counterparts. One possible explanation for the urban-rural disparity observed in this study was due to rural-urban migration. With the rapid industrialization and urbanization, a great number of rural labor force, including married women, had moved into urban areas for better job opportunities without changing their hukou status (Liang and Chen 2007), leaving their aged parents behind in the rural areas (Wang et al. 2015). According to the National Health and Family Planning Commission of China (National Health and Family Planning Commission of the People's Republic of China 2018), about 247 million rural people had moved to urban areas by the end of 2015. With the outflow of rural labor force, the elderly live separately from their children, resulting in the change of rural living style and the migrant young women are unable to provide the necessary care and support for the left-behind older parents. As a result, when the elderly in rural areas (whose daughter or daughter-in-law had moved to cities) need the care from their children, they can only rely on their spouse or hire someone to take care of them (Yin and Liu 2017). In contrast, adult children with urban hukou and their elderly parents usually live in the same city, and their living style has not changed fundamentally. When the elderly feel uncomfortable or sick, children can provide timely caregiving.

This study indicates that adult daughters-in-law provide more help to elders than do daughters, both in low-intensity and high-intensity care. This showed that the informal care provided by married women with rural hukou was more about "considering both parents and parents-in-law at the same time" rather than "considering only one side". 
By further analyzing this phenomenon of the urban-rural difference, we found significant difference in providing elderly care between daughters and daughters-in-law with rural hukou, but not with urban hukou. The most straightforward explanation for this phenomenon would be the role of the traditional culture in China. A Chinese proverb says, "A married daughter is just like water that has been poured-she doesn't belong to her parents anymore", which is particularly true in rural China. After marriage, to take care of parents-in-law would be the primary responsibility for the daughters-in-law (Greenhalgh 1985; Sun 2002), and they could not take care of their own parents properly. One study found that daughters-in-law experience less help from parents-in-law (Ingersoll-Dayton et al. 1996). These results suggest that the role of daughters in informal care is less than that of daughters-in-law.

We also found that low-intensity and high-intensity informal care showed opposite results in employment status among urban respondents, but it was not significant among rural respondents. Respondents with urban hukou generally have stable jobs. Compared with urban women, rural women can be divided into two groups. One group women with rural hukou come to cities as migrant workers, while others work nearby in rural areas. Therefore, employment status has a significant impact on urban respondents. Among respondents with urban hukou, employed women tend to provide low-intensity care rather than high-intensity care because high-intensity care requires more time and effort.

The results of Oaxaca-Blinder decomposition analysis demonstrated that the largest contributor to the overall gap between the rural and urban in providing informal care was education attainment that explained $25.10 \%$ of difference $(p<0.001)$ (Table 4$)$. Consistently, the multinomial logistic regression showed that women with higher education background were more likely to provide high-intensity caregiving, the relative risk ratios (RRR) value was around 1.9 (Table 2). Therefore, the observed urban-rural disparity might be due to the difference in education attainment. Previous studies support our results and found that the education level of women was positively correlated with the elderly caregiving in China (Zhang 2012). There are several possible explanations. First, it may be because that women with higher levels of education have more social resources and are better able to take care of the elderly (Huang 2014). On the other hand, urban women who are more educated than rural women tend to view care for older parents as a means of returning their parents with their investment repayments (Lee and Xiao 1998) because education has long been an important factor in social and personal development, and achieving higher education requires more parental and family investment. Although the government has been working to improve the education level of the rural labor force, the gap between urban and rural education is still very large. According to the 2010 census data, $37 \%$ of the population had a high school education level, only $8 \%$ of the population had a high school education level in rural areas. Therefore, improving the level of education for women, especially in the villages may help to promote the quality of care for the elderly. Other explained factors, such as household income per capita, were not significant in the results of Oaxaca-Blinder decomposition.

The present study has several limitations. First, information including weekly hours of informal care was self-reported, which could lead to recall bias. Second, because CHNS is a an open-cohort study whereas former participants may drop out and newcomers further join in subsequent surveys, we pooled 8 waves of data from 1993 to 2015 in order to obtain a decent sample size, which may confound the cohort effects over such a long period despite the fact we adjusted for period or time effects. Third, some omitted variables, such as the care recipient's marital status, were not available in the database, which may bias our estimates. 
Using a national sample of Chinese married women, we found that urban hukou holders were more likely to provide informal care for their elderly parents, both in low-intensity and high-intensity care, than their rural counterparts. From 1993 to 2015, the rural-urban disparities in informal care persisted, and in the high-intensity care, the disparities between urban and rural care tends to increase. We also found that education attainment was the most effective determinant in providing informal caregiving. Long-term care system in China should be established and improved to complement existing informal care, and policies should focus more on rural hukou holders and the less educated.

Funding The study was supported by the National Science Foundation of China (Grant Numbers 71774104, 71974117, 71473152 and 71003067) and the China Medical Board (16-257), Cheeloo Youth Scholar Grant, and Shandong University (Grant Numbers IFYT1810, 2012DX006).

Open Access This article is licensed under a Creative Commons Attribution 4.0 International License, which permits use, sharing, adaptation, distribution and reproduction in any medium or format, as long as you give appropriate credit to the original author(s) and the source, provide a link to the Creative Commons licence, and indicate if changes were made. The images or other third party material in this article are included in the article's Creative Commons licence, unless indicated otherwise in a credit line to the material. If material is not included in the article's Creative Commons licence and your intended use is not permitted by statutory regulation or exceeds the permitted use, you will need to obtain permission directly from the copyright holder. To view a copy of this licence, visit http://creativecommons.org/licenses/by/4.0/.

\section{References}

Bédard, M., Koivuranta, A., \& Stuckey, A. (2004). Health impact on caregivers of providing informal care to a cognitively impaired older adult: Rural versus urban settings. Canadian Journal of Rural Medicine, 9(1), 15-23.

Blinder, A. S. (1973). Wage discrimination: Reduced form and structural estimates. Journal of Human Resources, 8(4), 436-455.

Carmichael, F., \& Charles, S. (2003). Benefit payments, informal care and female labour supply. Applied Economics Letters, 10(7), 411-415.

Chen, L., Zhao, N., Fan, H., \& Coyte, P. C. (2015). Informal care and labor market outcomes: Evidence from Chinese married women. Research on Aging, 39(2), 345-371.

Du, P., \& Yin, S. (2012). The research of long-term care needs condition and tendency of the elderly. China Population Today, 3, 40.

Greenhalgh, S. (1985). Sexual stratification: The other side of "growth with equity" in East Asia. Population and Development Review, 11(2), 265-314.

Guthrie, D. (2011). One country, two societies: Rural-urban inequality in contemporary china by Martin King Whyte. China Review International, 18(3), 1219-1221.

Hanaoka, C., \& Norton, E. C. (2008). Informal and formal care for elderly persons: How adult children's characteristics affect the use of formal care in Japan. Social Science and Medicine, 67(6), 1002-1008.

$\mathrm{Hu}$, B. (2018). Projecting future demand for informal care among older people in China: The road towards a sustainable long-term care system. Health Economics Policy \& Law, 14(1), 1-21.

Huang, X. (2014). Analysis on the difference of social status between urban and rural women. Learning Theory, 34(02), 100-101. (in Chinese).

Ingersoll-Dayton, B., Starrels, M. E., \& Dowler, D. (1996). Caregiving for parents and parents-in-law: Is gender important? The Gerontologist, 36(4), 483-491.

Kosloski, K., Schaefer, J. P., Allwardt, D., Montgomery, R. J. V., \& Karner, T. X. (2002). The role of cultural factors on clients' attitudes toward caregiving, perceptions of service delivery, and service utilization. Home Health Care Services Quarterly, 21(3-4), 65-88.

Lan, L., \& Gong, C. (2010). Research on the relation between parental care and self-reported health of married women in Urban China. Population \& Development, 16(5), 52-59. (in Chinese).

Lee, Y. J., \& Xiao, Z. (1998). Children's support for elderly parents in urban and rural China: Results from a national survey. Journal of Cross-Cultural Gerontology, 13(1), 39-62. 
Lei, X., Sun, X., Strauss, J., Zhao, Y., Yang, G., Hu, P., et al. (2014). Health outcomes and socio-economic status among the mid-aged and elderly in China: Evidence from the CHARLS national baseline data. Journal of the Economics of Ageing, 4(34), 59-73.

Li, F., \& Otani, J. (2018). Financing elderly people's long-term care needs: Evidence from China. International Journal of Health Planning and Management, 33(2), 479-488.

Li, J., Shi, L., Liang, H., Ding, G., \& Xu, L. (2018). Urban-rural disparities in health care utilization among Chinese adults from 1993 to 2011. BMC Health Services Research, 18(1), 102.

Liang, Z., \& Chen, Y. P. (2007). The educational consequences of migration for children in China. Social Science Research, 36(1), 28-47.

Lin, W. (2014). Challenges of long-term care provisions for the elderly in urban China. China: An International Journal, 12(2), 144-160.

Liu, Z. (2005). Institution and inequality: The hukou system in China. Journal of Comparative Economics, 33(1), 133-157.

Liu, L., Dong, X.-Y., \& Zheng, X. (2010). Parental care and married women's labor supply in urban China. Feminist Economics, 16(3), 169-192. https://doi.org/10.1080/13545701.2010.493717.

Liu, H., Rizzo, J. A., \& Fang, H. (2015). Urban-rural disparities in child nutrition-related health outcomes in China: The role of hukou policy. Bmc Public Health, 15(1), 1-11.

Lu, B., Liu, X., \& Piggott, J. (2015). Informal long term care in China and population ageing: Evidence and policy implications. Population Review, 54(2), 28-41.

McKenzie, S. J., McLaughlin, D., Dobson, A. J., \& Byles, J. E. (2010). Urban-rural comparisons of outcomes for informal carers of elderly people in the community: A systematic review. Maturitas, 67(2), 139-143.

Mei, L., Yang, Z., Zhenyu, Z., Ying, Z., Litao, Z., \& Kun, C. (2013). Rural-urban differences in the longterm care of the disabled elderly in china. PLOS ONE, 8(11), e79955.

Meina, L., Qiuju, Z., Mingshan, L., Churl-Su, K., \& Hude, Q. (2007). Rural and urban disparity in health services utilization in China. Medical Care, 45(8), 767-774.

National Bureau of Statistics of China. (2018). The National Data.

National Bureau of Statistics of the People's Republic of China. (2012). China's first survey on the utilization of residents' time.

National Health Commission of the People's Republic of China. (2019). Guidelines on the establishment and improvement of elderly health service system.

National Health and Family Planning Commission of the People's Republic of China. (2018). Report on China's migrant population development-2018.

Oaxaca, R. (1973). Male-female wage differentials in urban labor markets. International Economic Review, 14(3), 693-709.

Rozario, P. A., \& Simpson, G. M. (2018). Social support and self-rated health of African american women informal caregivers: Urban and rural differences. Journal of Gerontological Social Work, 61(1), 16-30.

Schmitz, H., \& Westphal, M. (2017). Informal care and long-term labor market outcomes. Journal of Health Economics, 56, 1-18.

Shi, Z. (2014). The influence of family planning policy on family development ability and its policy implication. Journal of Public Administration, 4, 83-94. (in Chinese).

Sun, R. (2002). Old age support in contemporary urban china from both parents' and children's perspectives. Research on Aging, 24(3), 337-359.

Sung-Wan, K., Jae-Min, K., Robert, S., Kyung-Lyul, B., Su-Jin, Y., Il-Seon, S., et al. (2010). Correlates of caregiver burden for Korean elders according to cognitive and functional status. International Journal of Geriatric Psychiatry, 21(9), 853-861.

The State Council. (2019). The country actively responded to the medium - and long-term planning of population aging.

Treiman, D. J. (2012). The "difference between heaven and earth": Urban-rural disparities in well-being in China. Research in Social Stratification \& Mobility, 30(1), 33-47.

van Campen, C., de Boer, A. H., \& Iedema, J. (2013). Are informal caregivers less happy than noncaregivers? Happiness and the intensity of caregiving in combination with paid and voluntary work. Scandinavian Journal of Caring Sciences, 27(1), 44-50.

Van Houtven, C. H., Coe, N. B., \& Skira, M. M. (2013). The effect of informal care on work and wages. Journal of Health Economics, 32(1), 240-252.

Van Houtven, C. H., \& Norton, E. C. (2008). Informal care and Medicare expenditures: Testing for heterogeneous treatment effects. Journal of Health Economics, 27(1), 134-156.

Wang, G., Hu, M., Xiao, S., \& Zhou, L. (2017). Loneliness and depression among rural empty-nest elderly adults in Liuyang, China: A cross-sectional study. British Medical Journal Open, 7(10), e16091. 
Wang, S., Kou, C., Liu, Y., Li, B., Tao, Y., D’Arcy, C., et al. (2015). Rural-urban differences in the prevalence of chronic disease in northeast China. Asia-Pacific Journal of Public Health, 27(4), 394-406.

Wong, Y. C., \& Leung, J. (2012). Long-term care in China: Issues and prospects. Journal of Gerontological Social Work, 55(7), 570-586.

World Health Organization. (2015). World report on ageing and health.

World Health Organization. (2016). China country assessment report on ageing and health.

$\mathrm{Wu}, \mathrm{X}$. (2011). The household registration system and rural-urban educational inequality in contemporary China. Chinese Sociological Review, 44(2), 31-51.

Wu, H., \& Lu, N. (2017). Informal care and health behaviors among elderly people with chronic diseases. Journal of Health, Population and Nutrition, 36(1), 40.

Wu, X., \& Treiman, D. J. (2004). The household registration system and social stratification in China: 1955-1996. Demography, 41(2), 363-384.

$\mathrm{Xu}, \mathrm{L} .$, \& Chi, I. (2010). Intergenerational support and self-rated health among chinese older adults in onechild families: Urban and rural differences. Social Development Issues, 32(14), 48-61.

Yang, F. (2007). An analysis of the historical stages and prospects of China's rural family old-age security. Economic Exploration, 4, 182-186. (in Chinese).

Yang, W., He, A. J., Fang, L., \& Mossialos, E. (2016). Financing institutional long-term care for the elderly in China: A policy evaluation of new models. Health Policy Plan, 31(10), 1391.

Yi, Z., George, L., Sereny, M., Gu, D., \& Vaupel, J. W. (2016). Older parents enjoy better filial piety and care from daughters than sons in China. The American Journal of Medicine (New York), 3(1), 244-272.

Yin, J., \& Liu, Y. (2017). Number of children, living style and family intergenerational support - from the perspective of urban-rural differences. Journal of Wuhan University, 70(5), 66-77. (in Chinses).

Zeng, Y., Hu, X., Li, Y., Zhen, X., Gu, Y., Sun, X., et al. (2019). The quality of caregivers for the elderly in long-term care institutions in Zhejiang Province, China. International Journal of Environmental Research and Public Health, 16(12), 2164.

Zhang, Q. (2012). Family care by women to old parents and its determinants. Doctoral dissertation, Fudan University. (in Chinese).

Zhang, Z., \& Treiman, D. J. (2013). Social origins, hukou conversion, and the wellbeing of urban residents in contemporary China. Social Science Research, 42(1), 71-89.

Zhang, B., Zhai, F. Y., Du, S. F., \& Popkin, B. M. (2014). The China health and nutrition survey, 19892011. Obesity Reviews, 15(Suppl 1), 2-7. https://doi.org/10.1111/obr.12119.

Zhou, X., \& Tian, F. (2011). A comparative study on the health care and medical service consumption of urban and rural households in China. Journal of Economic Studies, 38(1), 17-29.

Zhu, Y., \& Osterle, A. (2017). Rural-urban disparities in unmet long-term care needs in China: The role of the hukou status. Social Science and Medicine, 191, 30-37.

Publisher's Note Springer Nature remains neutral with regard to jurisdictional claims in published maps and institutional affiliations.

\title{
Affiliations
}

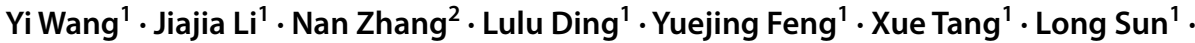 Chengchao Zhou ${ }^{1,3}$}

\author{
Yi Wang \\ wangyi031104@163.com \\ Jiajia Li \\ lijiajia@sdu.edu.cn \\ Nan Zhang \\ nan.zhang-2@manchester.ac.uk \\ Lulu Ding \\ 1531520959@qq.com \\ Yuejing Feng \\ fengyuejing1994@163.com
}


Xue Tang

tessie0929@163.com

Long Sun

sunlong@sdu.edu.cn

1 School of Public Health, Shandong University, Jinan 250012, China

2 Social Statistics, Manchester Institute for Collaborative Research on Ageing, University of Manchester, Manchester, UK

3 NHC Key Laboratory of Health Economics and Policy Research, Shandong University, 44 Wen-hua-xi Road, Jinan 250012, Shandong, China 